\title{
Investigation of suspended sediment transport using ultrasonic techniques
}

\author{
Bjørnø, Irina; Jensen, Leif Bjørnø
}

Published in:

Proceedings of the Oceans Engineering for Today's Technology and Tomorrow's Preservation

Link to article, DOI:

10.1109/OCEANS.1994.364210

Publication date:

1994

Document Version

Publisher's PDF, also known as Version of record

Link back to DTU Orbit

Citation (APA):

Bjørnø, I., \& Jensen, L. B. (1994). Investigation of suspended sediment transport using ultrasonic techniques. In Proceedings of the Oceans Engineering for Today's Technology and Tomorrow's Preservation (Vol. Volume 3, pp. 284-286). IEEE. https://doi.org/10.1109/OCEANS.1994.364210

\section{General rights}

Copyright and moral rights for the publications made accessible in the public portal are retained by the authors and/or other copyright owners and it is a condition of accessing publications that users recognise and abide by the legal requirements associated with these rights.

- Users may download and print one copy of any publication from the public portal for the purpose of private study or research.

- You may not further distribute the material or use it for any profit-making activity or commercial gain

- You may freely distribute the URL identifying the publication in the public portal

If you believe that this document breaches copyright please contact us providing details, and we will remove access to the work immediately and investigate your claim 


\title{
Investigation of Suspended Sediment Transport Using Ultrasonic Techniques.
}

\author{
I. K. Bjørnø and L. Bjørnø \\ Department of Industrial Acoustics \\ Technical University of Denmark, \\ Building 425, DK-2800 Lyngby, Denmark
}

Abstract - The results of the initial experimental studies involving the scattering of ultrasonic signals from canonical and non-canonical shaped suspended particles with known elastical qualities are reported. These results have formed the basis for the development of a numerical model for ultrasound propagation through low-concentration suspensions of sand particles.

\section{INTRODUCTION}

During recent years the importance of development of ultrasonic methods for the investigation of the transport of suspended marine sediments in rivers and in coastal regions has been demonstrated. Knowledge about the concentration, the size distribution, sediment type mass transport, chemical properties etc. related to suspended sediments is of great importance for transportation, off-shore activities, harbour construction and land survey. Two main acoustical procedures have been developed and used in laboratory studies, (1) high frequency resonance backscattering and (2) attenuation acoustic spectroscopy. Both approaches are based on the same fundamental concepts related to the interaction process between ultrasonic signals and suspended sediment particles.

The interest in the problems of sound propagation through suspensions of sediments has been developed over the last ten years due to the noticeable progress in ultrasonic techniques. The advantages of use of broadband ultrasonic methods compared to more traditional ones are, that a single instrument can provide, nondestructively, temporal resolutions of high accuracy of quantities desirable for the estimation of characteristics of sediments in their natural environments and in real time.

The use of acoustical methods for the estimation of suspended sediment concentration in the ocean has been suggested long time ago [1]. Only little was done for many years, but progress has been made over the last decade through theoretical as well as experimental studies [2-4]. Although these studies have demonstrated the potential of acoustic remote sensing techniques for sediment transport investigations, several difficulties still remain, particular in relation to the choice of the most appropriate model for the sediment particles in suspension.

\section{SEDIMENT PARTICLES}

In natural condition in the ocean, close to the seabed, suspended sediments form a thin layer of several tenths of $\mathrm{cm}$ from the bottom consisting of different groups of particles with different physical properties. The suspensions comprise: silt, mud, clay and sand with an average size distribution between $5 \mu \mathrm{m}$ and $1 \mathrm{~mm}$. Laboratory studies of ocean sediments by optical technique have shown the irregular shape of the particles. For sand particles of a $200 \mu \mathrm{m}$ size the most probable shape is an ellipsoid, which is not far from spherical with the main axis: $D_{1}=1.3 D_{2}$ [5]. The octahedron shape is typical for $100 \mu \mathrm{m}$ sand particles, and for small size sand particles (diameter 10-30 $\mu \mathrm{m}$ ) the shape is close to a cube or a tetrahedron. Micro photographs of clay samples have shown a plate-like shape of the particles with a thickness of a few micrometers and a dominating length size of $5-10 \mu \mathrm{m}$ [4]. This shape is closely related to the crystal structure. The typical size of the silt particles ranges from 10 to $50 \mu \mathrm{m}$ [5].

Another important characteristic feature of suspended sediments is the concentration. Two different regions of concentrations have been of particular interest to model studies. They are: low sediment concentrations $\left(<0.1 \mathrm{~kg} / \mathrm{m}^{3}\right)$, and high sediment concentrations $\left(<10 \mathrm{~kg} / \mathrm{m}^{3}\right)$. For ultrasonic studies of high sediment concentrations, the effects of multiple scattering, flocculation and possible nonlinear acoustical influences should be considered.

\section{EXPERIMENTAL INVESTIGATIONS OF INDIVIDUALLY SUSPENDED PARTICLES}

\section{A. Theory}

Two ultrasonic based methods have recently been developed for sediment transportation studies. Acoustic (back)scattering [6] and attenuation spectroscopy [4]. It is well known, that the level of the scattered signal amplitude depends on the size, the number (concentration), the shape (including surface topography) and the elastic properties of the scatterers and, therefore, it can be used for determination of parameters of suspended particles. In the case of attenuation spectroscopy the same parameters (size, number, shape and elasticity) influence the attenuation spectra of ultrasonic signals propagating in suspensions of sediments, due to the fact that in this case the attenuation is mostly due to scattering.

Attenuation spectroscopic methods have been developed and applied to field studies of suspended sediments to a larger extent than scattering methods. The implementation of absolute scattering measurements with high accuracy and proper interpretation of experimental results demands the existence of realistic models for the scattering, and there is still a lack of fundamental knowledge in this area. A model consisting of rigid, movable, noninteractive quartz spheres for description of suspensions of sand particles still remains the most advanced 
theoretical model, which gives the best fit to experimental results [7]. Approaches using the modified form functions known as a "high pass model" yield a first attempt to describe the process of single particle scattering for particles of nonspherical shapes [8]. A realistic estimation of the concentration and size distribution of suspended particles from the results of backscattering measurements can only be obtained after a realistic definition of the (back)scattering form function $\left|f_{w}\right|$ as a function of frequency and particle size. Finally, the experimental values for the form function are higher than predicted from the theory based on a heuristic approach.

The backscattered signal from a sphere $P$, within the beam of a transducer can be calculated from the experimentally measured parameters [8]:

$$
P_{\alpha}=a P_{0} r_{0} \frac{D^{2}(\theta)}{2 r^{2}} f_{\alpha} e^{-2 \alpha r}
$$

where: $P_{0}$ is the transmitted pressure at range $r_{0} ; r$ is the range to the particle; $\mathbf{D}(\boldsymbol{\theta})$ is the transducer directivity function; $\theta$ denotes the angle between the direction to the particle and acoustical axis; $a$ is the particle radius; $\alpha$ is attenuation due to absorption in water; and $f_{-}$is the farfield form function. Theoretical values of the farfield form function for the sphere can be calculated analytically using well-known procedures [8]. For particles of arbitrary shape an analytical expression for the form function does not exist. In order to examine the dependence of the form factor $\left|f_{-}\right|$on the shape of the suspended particles, preliminary laboratory studies were performed.

\section{B. Experimental set-up}

The experiments were carried out in a laboratory test tank of the dimensions $2 \times 0.5 \times 0.5 \mathrm{~m}$. The measurements were made using two transducers: (1) a Reson TC 3012 (operational frequency range $900-1200 \mathrm{kHz}$; diameter of the active element is $16 \mathrm{~mm}$ ), and (2) a Panametrics A301S (operational frequency range 300-900 kHz; diameter of the active part is $25 \mathrm{~mm}$ ). The transmitting and receiving sensitivities of the transducers were measured using a probe type PVDF needle hydrophone. The backscattered signals from a target were used to determine the form function according to expression (1). The transducers were emitting pulses typically of $75 \mu$ s duration. The backscattered signal was amplified, filtered and averaged to improve the signal/noise ratio. The signals were repeated 10 times per second. The signals were analyzed using a digital oscilloscope, Tektronix 2432A. The targets employed were placed in the farfield of the transducers (typically, distance $r=50$ $\mathrm{cm}$ ) suspended in a $350 \mu \mathrm{m}$ diameter nylon line and fixed by a thin film of epoxy glue. The material of the scatterers studied was steel, and the shapes investigated were spheres and cubes with their characteristic dimensions covering kavalues between 5 and 30 . In the case of cubes, the value of a is defined as: $a=\sqrt[3]{3} V / 4 \pi$, where $V$ is the volume of the cube. The material qualities of steel used for the computation of the form function are the following: density - $7850 \mathrm{~kg} / \mathrm{m}^{3}$, compressional velocity $-5960 \mathrm{~m} / \mathrm{s}$, shear velocity $-3235 \mathrm{~m} / \mathrm{s}$.

\section{Results and discussions}

First, a series of calibration experiments for steel spheres were performed, and a comparison of the experimental data for the form function with the theoretically predicted ones is shown in Fig. 1. The figure shows a good agreement between the two sets of results, which reflects the experimental accuracy obtained. In the next step the backscattering from a suspended steel cube was studied. Some experimental results obtained for the form function of a steel cube at normal and edge incidence are shown in Fig. 2 and 3. The geometry of the experimental arrangement is shown in Fig. 4. The limitations of the range of ka-values due to the choice of transducers and of angles of incidence lead to some difficulties for the final interpretation of the experimental data. But even from the first results it can readily be seen that there is a significant difference between form functions for spheres and cubes. The main feature of the form function for cubes is a much higher absolute level of the form function $\left|f_{-}\right|$compared with the one for spheres.

For a distribution of particles with an arbitrary shape and with random orientation in space the resonance structure of the backscattered signals, due to elasticity and to differences in shape and orientation, will be completely lost. Instead for an absolute form function, "the orientation average" form function should be used for the estimations of the concentration of the suspended particles from backscattering signals. This was verified partly by the experiments [9-10].

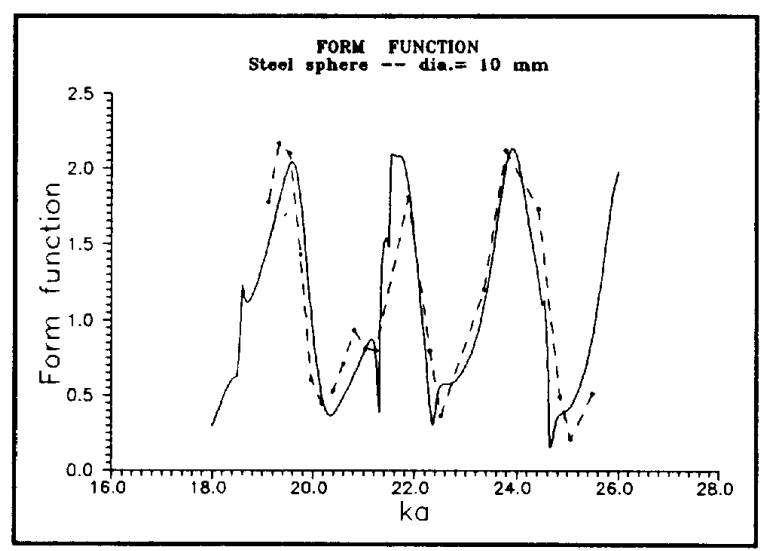

Fig. 1. Comparison of the computed form function for the steel sphere (solid line) with the experimental data (dashed line). 


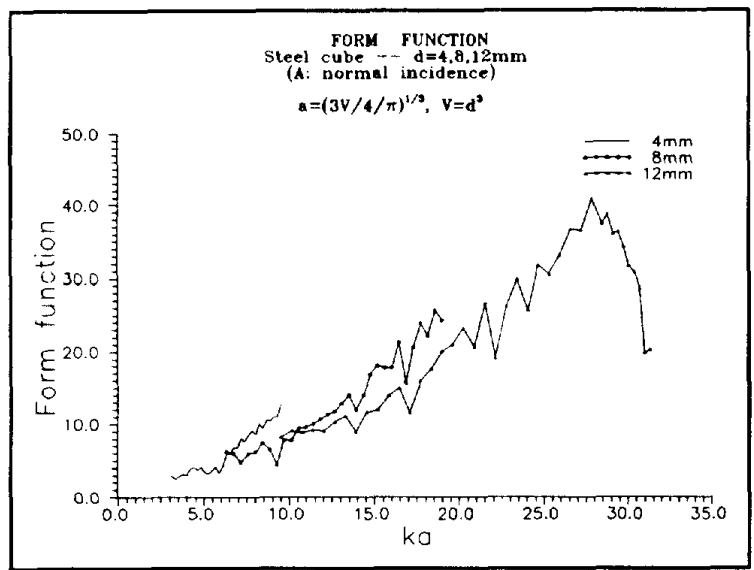

Fig. 2. Measured form function for the steel cubes (with the side sizes $4 \mathrm{~mm}$, $8 \mathrm{~mm}$ and $12 \mathrm{~mm}$ ) for normal incidence.

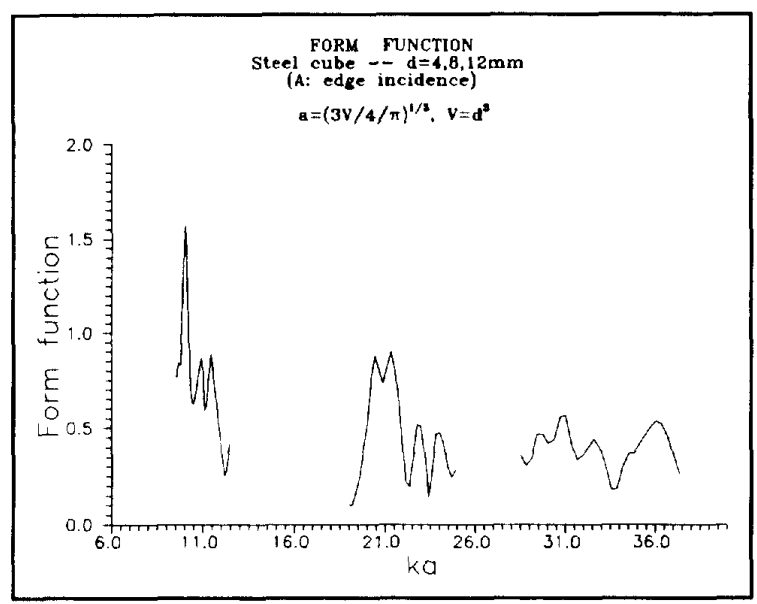

Fig. 3. Measured form function for steel cubes (with the side sizes $4 \mathrm{~mm}, 8 \mathrm{~mm}$ and $12 \mathrm{~mm}$ ) for edge incidence.

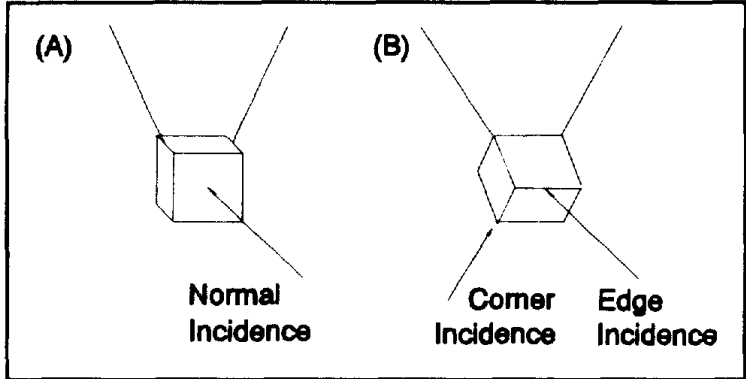

Fig. 4. Experimental geometry for backscattering from cubes.

\section{CONCLUSION}

Experimental studies performed in the laboratory provide evidence for that the concept of "orientation average form function" applied for backscattering spectroscopy is useful for correct interpretation of the experimental results when arbitrary shaped suspended particles are studied. The above discussion indicates that based on the present state-of-the-art, it is not possible to design a general method of analysis using acoustical investigations of qualities of suspended sediment particles in real environments. This is possible for perfectly spherical particles only, for which theoretically well-developed models are available. However, such models are not yet available for irregularly shaped particles. The experimental determination of the orientation average form function for particles of different shapes characterizing real sand will be the next step in the realization of the research programme related to the MAST project: SMART/ISUSAT.

\section{ACKNOWLEDGMENTS}

We would like to thank Guo Jijie for helping with the collection the laboratory data.

\section{REFERENCES}

[1] R.S. Dietz, "Deep scattering layer in the Pacific and Atlantic Oceans", J. Mar. Res., vol. 7, pp. 430-442, 1948.

[2] A.E. Hay, "On the remote acoustic detection of suspended sediment at long wavelength", J. Geoph. Res., Vol. 88 (c12), pp.7525-7542, 1983.

[3] Y. Ma, V.K. Varadan, V.V. Varadan, and K.W. Bedford, "Multifrequency remote acoustic sensing of suspended mate-rials in water", J. Acoust. Soc. Am., Vol. 74, pp. 581$585,1983$.

[4] A.S. Schaafsma, "Acoustic measurement of concentration and size of sediment particles suspensions", in Ultrasonics International Conference Proceedings, Butterworth, 1989, pp.388-393.

[5] J.P.M. Syvinski, K.W.G. Leblanc, and K.W. Asprey, in Principles, Methods an application of particle size analysis, by J.P.M. Syvinski (Ed.), Cambridge University Press, UK, 1991, Chapter 13.

[6] A.E. Hay, "Sound scattering from a particle-laden, turbulent jet", J. Acoust. Soc. Am., Vol. 90, pp. 2055-2074, 1991.

[7] J. Sheng, and A.E. Hay, "An examination of the spherical scatterer approximation in aquaous suspensions of sand", $J$. Acoust. Soc. Am., Vol 83, pp.598-610, 1988.

[8] P.D. Thorne, "Backscattering by a suspension of spheres", J. Acoust. Soc. Am., Vol 92, pp. 978-986, 1992.

[9] A.M. Crawford and A.E. Hay, "Determining suspended sand size and concentration from multifrequency acoustic backscatter", J. Acoust. Soc. Am., Vol. 94, pp. 3312-3324, 1993.

[10] P.D. Thorne, P.J. Hardcastle, and R.L. Soulsby, "Analysis of acoustic measurements of suspended sediments", $J$. Geoph. Res., Vol. 98, pp. 899-910, 1993. 